\title{
NO CURSO DAS MUDANÇAS
}

\author{
Iracema Brandão Guimarães*
}

Um longo período se passou desde que tivemos o último editorial. A motivação geralmente tem sido uma comemoração, uma mudança importante, ou um lançamento de números publicados. Em retrospectiva, naquele editorial se comemorava vinte anos de existência desta revista (1987 a 2007), enquanto no ano de 2019, juntava-se a comemoração dos cinqüenta anos de existência do Centro de Recursos Humanos, aos trinta anos de atividade ininterrupta da revista que evoluiu, na penúltima fase, para veículo de publicação quadrimestral. Portanto, foi um longo período no qual enfrentamos mudanças em resposta a desafios que nos levavam a preservar uma trajetória de veículo qualificado de difusão da pesquisa institucional.

Uma nova realidade das revistas científicas e a difícil conjuntura que atravessamos neste ano de 2020 levou a equipe responsável a empreender uma nova mudança, evoluindo agora para o formato de Publicação Contínua, com Volume Anual Único, iniciado no número33. A mudança de formato atende a novas

* Universidade Federal da Bahia. Centro de Estudos e Pesquisas em Humanidades.

Estrada de São Lázaro, 197, Federação, CEP 40210-730, Salvador, Bahia - Brasil. iracema.brandao60@gmail.com https://orcid.org/0000-0003-3533-6180 exigências, implicando em passar a veicular os textos na forma exclusivamente on-line, contendo três Dossiês sobre temas específicos que continuarão sendo organizados por autores de elevada experiência acadêmica, além de artigos livres, resenhas e informes. Portanto, com a adesão a este novo sistema, e novos controles técnicos, acreditamos favorecer aos autores e também aos leitores ao acompanharmos as diretrizes mais atuais da divulgação científica. Mudamos, mas preservamos a nossa identidade. No âmbito da difusão da pesquisa institucional damos continuidade às diretrizes de sintonizarmos com uma dimensão crítica das ciências sociais, em sentido amplo, conforme assinalou Ivo (2007). Mantém-se, portanto, a contribuição deste veículo com o debate acadêmico plural e interdisciplinar, oferecendo espaço de divulgação, preservando o papel do atual Centro de Estudos e Pesquisas em Humanidades que sedia a revista, através dos seus participantes, interlocutores, e colaboradores, em busca da renovação de antigos elos, e de novas dimensões teóricas e empíricas que sustentem a tarefa de pensar criticamente a sociedade nacional e global.

Renova-se também o papel da interdisciplinaridade na construção de pontes. Con- 
forme assinalou Salles, torna-se importante a construção de

[...] base semântica comum entre pesquisadores de matrizes disciplinares distintas ou de tradições teórico-metodológicas relativamente afastadas, combatendo o estigma outrora denunciado por R. Carnap, segundo o qual o trabalho interdisciplinar, quando pioneiro ou fecundo, não seria visto na instituição universitária como construtor de pontes, mas antes, como perturbador e invasivo (Salles, 2012, p. 10).

Nos diálogos da Sociologia (área temática central) com suas áreas afins, apostamos também na abertura de caminhos, mesmo em conjunturas políticas e administrativas diversas, como a atual, com seus constantes desafios que resultaram em amplos cortes nas instituições de fomento à pesquisa no ano de 2019, principalmente na área de Ciências Humanas, mas sem interromper os nossos esforços, tal como nas equipes anteriores, em busca de novas formas de responder a velhas perguntas, lembrando Maria Célia Paoli (1991). Além disso, mantemos as possibilidades de apoio às Pós-Graduações, e suas constantes redefinições de núcleos e formatações das linhas de pesquisa.

Guardando-se as devidas diferenças, Sousa lembra que:

A sociologia da cultura contribui na elaboração... de um problema, ao relacionar a edição tradicional com as tendências contemporâneas no campo editorial. Esta problemática é relativa ao papel histórico e social do editor que hoje é questionado pela edição na Web (Sousa, 2015, p. 215).

Temos, portanto, outras tendências contemporâneas que se avizinham como a possível adesão ao pré-print, aos critérios de apreciação กิ e suas novas dinâmicas de submissão, ou ainda, Iracema Brandão Guimarães - Professora Titular da Universidade Federal da Bahia, vinculada ao Departamento de Sociologia de 1980 a 2019, credenciada como Professora Permanente do Programa de Pós Graduação em Ciências Sociais. Tem experiência docente na área de Teoria Sociológica, atuando em pesquisas relacionadas aos seguintes temas: sociologia do trabalho, sociologia urbana, sociologia da família. Exerceu o cargo de Coordenadora do Centro de Estudos e Pesquisas em Humanidades - CRH da UFBA no período de 2009 a 2011 e de Coordenadora do Programa de Pós-Graduação em Ciências Sociais da UFBA de 1994 a 1996 e de 2002 a 2004. Atualmente é Pesquisadora do CNPq, desenvolvendo projeto no Centro de Estudos e Pesquisas em Humanidades (CRH) - UFBA. Editora Cientifica da Revista Caderno CRH, Qualis A1. aos repositórios de artigos, em geral, mais facilmente ajustáveis às ciências exatas e menos às humanas. Esse também é o caso do debate sobre a ciência aberta que acena com uma proposta de abertura progressiva da revisão de artigos com base em critérios que modificam os processos de revisão já conhecidos e aceitos.

Seguindo, portanto, o novo formato, já sob a forma da Publicação Contínua, encontra-se disponível o Dossiê número 88 "Participação Institucional e Ativismo no Brasil Contemporâneo", organizado por Wagner de Melo Romão, Françoise Montambeault, e Frédéric Louault e, em seguida, o Dossiê número 89 "60 anos de A Condição Humana, de Hanna Arendt", organizado por Ingrid Cyfer (Unifesp), Denise Vitale (Ufba), Renata Nagamine (Ufba). Além disso, o último Dossiê do ano, em elaboração, promete uma interessante reflexão sobre a pioneira do feminismo acadêmico brasileiro, "50 anos da Obra de Heleieth Saffioti". Esperamos que nossos esforços sejam bem acolhidos pelos autores e leitores e desejamos que continuem a acessar a Revista Caderno CRH.

\section{REFERÊNCIAS}

IVO, Anete. Editorial, Caderno CRH v. 20, no. 50, maioSão Paulo, v. 31, p. 107-121, 1991.

SALLES, João Carlos. Conhecimento e Ação: entre laços teóricos e redes institucionais. Caderno CRH, Salvador, V. 25, N. SPE 02, 2012.

SOUSA, Antonio Paulino de. Gênese Social do Editor e as Novas Condições de Produção do Livro. Caderno CRH, Salvador, v. 28, n. 73, p. 215-230, Jan./Abr. 2015. agosto, 2007. 